\title{
Neoliberalismo e Educação Ambiental: uma leitura crítica sobre as relações público-privadas entre escolas e o agronegócio
}

\section{Carolina Borghi Mendes ${ }^{1}$ e Jandira Liria Biscalquini Talamoni ${ }^{2}$}

1 Profa. Ma. na Universidade Estadual do Norte do Paraná (UENP-CJ), campus, Jacarezinho, Centro de Ciências Humanas e da Educação, Colegiado de Ciências Biológicas. Doutoranda em Educação para a Ciência, Faculdade de Ciências, UNESP, Bauru, Brasil. E-mail: carolina.mendes@uenp.edu.br

2 Profa. Dra. no Programa de Pós-Graduação em Educação para a Ciência, Faculdade de Ciências, UNESP, Bauru, Brasil. E-mail: talamoni@fc.unesp.br

RESUMO: Defendemos a Educação Ambiental (EA) como um processo educativo que deve ser desenvolvido na educação escolar, comprometido com formação de indivíduos críticos que busquem a construção de uma sociedade ecologicamente equilibrada e socialmente justa. No presente estudo nos propomos discuti-la considerando os pressupostos neoliberais que, por razões concretas, delinearam o cenário educacional, possibilitando e fortalecendo as relações público-privadas entre as escolas públicas e o setor empresarial, em especial o do agronegócio. A escolha dessa análise se justifica, primeiramente, pela defesa de que o papel da educação escolar é o de possibilitar às classes trabalhadoras o acesso ao conhecimento sistematizado e, nesse sentido, é um ato político que não pode ser descaracterizado por ações ideológicas que valorizam os interesses do capital, nem mesmo na EA; em segundo lugar, por entendermos que o agronegócio tem grande relevância político-econômica e cultural no Brasil, com características históricas de degradação socioambiental e com forte inserção nas escolas públicas na região de Ribeirão Preto, por estratégia da Associação Brasileira do Agronegócio (ABAG). Temos como fundamento o Materialismo Histórico-Dialético, a favor da Educação Ambiental Crítica, em diálogo com os pressupostos da Pedagogia Histórico-Crítica. A discussão se concentra na inserção do setor privado em questão nas escolas públicas pela EA em decorrência do neoliberalismo, nas interferências geradas por esse processo à educação escolar pública e na necessidade de enfrentarmos as parcerias público-privadas.

Palavras-chave: Neoliberalismo; Educação escolar; Educação Ambiental Crítica; Parcerias Publico-Privadas; Agronegócio.

Neoliberalism and Environmental Education: a critical reading on public-private relations between schools and agribusiness

ABSTRACT: We defend Environmental Education (EE) as an educational process that must be developed in school education, committed to the formation of critical individuals who seek the construction of an ecologically balanced and socially just society. In the present study we propose to discuss it considering the neoliberal assumptions that, for concrete reasons, outlined the educational scenario, enabling and strengthening public-private relations between public schools and the business sector, especially agribusiness. The choice of this analysis is justified, first, by the defense that the role of 
school education is to enable the working classes to access systematized knowledge and, in this sense, it is a political act that can not be characterised by ideological actions that value the interests of capital, not even in EE; Secondly, because we understand that agribusiness has great political-economic and cultural relevance in Brazil, with historical characteristics of socio-environmental degradation and with strong insertion in public schools in the region of Ribeirão Preto, by strategy of the Brazilian Agribusiness Association (BAA). We are based on Historical-Dialectical Materialism, in favor of Critical Environmental Education, in dialogue with the assumptions of Historical-Critical Pedagogy. The discussion focuses on the insertion of the private sector in question in public schools by EA as a result of neoliberalism, the interference generated by this process to public school education and the need to face public-private partnerships.

Keywords: Neoliberalism; Schooling; Critical Environmental Education; Public-Private Partnerships; Agribusiness.

\section{INTRODUÇÃO}

Os diversos eventos relacionados à Educação Ambiental (EA) no cenário nacional por meio da formulação de leis - especificamente a Lei 9597/99 -, coletivos, movimentos sociais, grupos de estudos, cursos de formação inicial e continuada delinearam as concepções e ações educativas ambientais a serem desenvolvidas em difenrente espações, inclusive na escola pública.

Ao entendermos a EA no ambiente escolar devemos considerar as influências que este, em si, exerce sobre o processo educativo ambiental, incluindo os condicionantes objetivos e subjetivos nele existentes. Não se pode ignorar que a configuração da educação escolar no Brasil também carrega consigo traços marcantes da história e dos aspectos políticos, econômicos e culturais do país.

Sobre isso, Loureiro e Lamosa (2011) apontam que a EA formal está vinculada à situação da escola pública no Brasil que, historicamente, secundariza as funções educativas essenciais à formação humana. Corroborando, Souza (2014) afirma que a EA tem suas origens atreladas às perspectivas conservacionistas, que repercutem ainda hoje nas atividades propostas e realizadas no contexto escolar. As ações de EA, por vezes fragilizadas e pontuais, que ainda se inserem nas escolas se devem ao fato da própria escola pública brasileira ser contraditória, pautando-se "de um modo geral, em relações sociais que reproduzem ou reforçam as desigualdades sociais" (idem, p. 28).

O modelo educacional mundial sofreu interferências diretas do neoliberalismo globalizado, associado ao pragmatismo político, fato que se evidencia desde o final da década de 1980, com o Consenso de Washington e, na decada seguinte, com os direcionamentos do Banco Mundial às políticas educacionais no Brasil. As transformações político-econômicas possibilitaram aos empreendedores enxergar, na escola pública brasileira, o espaço para sua inserção e atuação (FIGUEIREDO et al., 2016). Intensificaram-se as parcerias entre os setores públicos, privados e a sociedade civil, disseminando-se um discurso baseado na responsabilidade social, já que apenas o Estado não conseguiu assumir e resolver todos os 
problemas sociais, cabendo ao empresariado "ajudá-lo" por meio do desenvolvimento de projetos baseados na ação participativa "em prol da educação" (NEVES, 2010).

Mas, para apreender por que o empresariado resolveu "ajudar", levemos em conta as considerações expressas a seguir.

Lombardi (2016, p. 63) relembra que "Marx entendeu a crise como o colapso das bases que regem o funcionamento de uma determinada formação social ou de um determinado modo de produção, fazendo a distinção entre crises gerais e parciais". As crises parciais (ou conjunturais) não apresentam uma profunda transformação política, econômica ou social, concentrando-se em expressões particularmente pontuais. Sobre elas, Saviani (2016) afirma que:

[...] as crises são inerentes ao capitalismo como forma metabólica de desenvolvimento social. Mas as crises com as quais o capitalismo convive e das quais se alimenta são crises parciais, conjunturais, relativas a determinados aspectos que podem ser controlados internamente, sem chegar a colocar em questão a totalidade da forma social capitalista. Tais crises configuram momentos de aguçamento das contradições que movem o próprio desenvolvimento capitalista e que, ao afetar, ainda que severamente, aspectos determinados do conjunto, não chegam a ameaçar sua sobrevivência, pois o sistema dispõe de mecanismos que lhe permitem deslocar as contradições críticas, contornando a crise e prosseguindo em sua marcha ascensional (SAVIANI, 2016, p. 31-32).

Para atender as exigências das "crises" parciais do capital - ainda que seja inegável a crise geral e estrutural que emerge deste sistema na atualidade -, a EA foi incorporada e difundida por diferentes instâncias da sociedade, incluindo as ligadas ao cenário educacional e às pertencentes ao mercado. Dessa forma, a partir de 1990, a pauta ambiental se consolidou como importante ferramenta de mercado e de atuação empresarial, além de se instaurar como integrante de um dos eixos transversais do processo educativo escolar (eixo meio ambiente) da Lei de Diretrizes e Bases da Educação (LDB, 1996). Ainda naquele período, tivemos a promulgação da Política Nacional de Educação Ambiental (PNEA) que contribuiu com o discurso colaborativo de que todos deveriam realizar a EA, em todos nos espaços educativos.

Vimos, desde então, uma parceria supostamente neutra e solidária que culminou no fortalecimento de parcerias público-privadas pela EA. A educação passou a fazer parte de um novo melodrama bem estruturado e com suposto final aprazível: o cenário é a escola pública, a temática é a preocupação ambiental e, por fim, os atores são os diferentes setores do empresariado. Loureiro e Lima apontam que:

Setores do empresariado no Brasil, a partir da segunda metade da década de 1990, tiveram na EA associada à promoção da sustentabilidade, com um forte vetor escolar e outro na criação de espaços DE ATUAÇÃO FORA DA ESCOLA que afirmam o diálogo e o consenso e negam os conflitos estruturais, uma das estratégias de educação política. Essa estratégia foi identificada na esfera federal por intermédio da ação do Instituto Ethos e do Instituto Ecoar para Cidadania, na adesão dos empresários ao ideário da responsabilidade social e na direção da Política Nacional de EA (PNEA) (LOUREIRO; LIMA, 2012, p. 293). 
Assim, a escola passa a ser convertida num espaço de disseminação de ideologias ligadas a valorização dos interesses do capital. Essa ampla adesão acarreta à EA e à comunidade escolar a necessidade de reflexão sobre a diferenciação teórica e metodológica existente nas ações propostas, ao mesmo tempo em que exige compreender as divergências ideológicas por detrás de cada ação. Isso porque, historicamente, a educação escolar se colocou "ao propósito não só de fornecer os conhecimentos e o pessoal necessário à máquina produtiva em expansão do sistema do capital, como também gerar e transmitir um quadro de valores que legitima os interesses dominantes" (MÉSZÁROS, 2008, p. 35, grifo do autor). Apesar da necessidade citada, pouco se avançou o entendimento desse cenário dentro das escolas.

A concepção de colaboração, a partir da EA, nas escolas públicas merece grande atenção, se sabemos serem essas difusoras de ideologias em nossa sociedade. Defendemos que o papel da escola é socializar os saberes elaborados pela cultura, ou seja, possibilitar aos sujeitos a apropriação de um conjunto sistematizado de conhecimentos que os instrumentalizem para a prática social transformadora (SAVIANI, 2012), exigindo que analisemos, sob a ótica da transformação do modelo societário vigente, a inserção do empresariado no espaço escolar público.

Nesse sentido, uma questão inicial para nortear nossa reflexão é: quais seriam os motivos, intenções e consequências da inserção, na escola pública, de instituições relacionadas ao setor privado, especialmente por meio de atividades consideradas como EA ou relacionadas à responsabilidade "socioambiental" no contexto neoliberal? Tal questionamento traz à tona a importância de entendermos que essa inserção não deve ser naturalizada na sociedade atual, reforçando sua aceitação pela comunidade escolar. Trata-se de um tipo de relação público-privada que inviabiliza o desenvolvimento de ações de EA numa perspectiva crítica e reforça ideologias neoliberais que se respaldam na tentativa de manter as desigualdades socioambientais, intensificando a própria degradação ambiental (MENDES, 2015), descaracterizando o papel da educação escolar pública como um importante mecanismo de formação humanizadora em busca da transformação social (SAVIANI, 2012).

Tendo como embasamento teórico-metodológico o Materialismo Histórico-Dialético e posicionando-nos a favor da EA Crítica (LAYRARGUES; LIMA, 2011; TOZONI-REIS, 2012), o presente artigo tem por objetivo analisar os motivos e consequências da inserção de instituições ligadas ao setor privado nas escolas públicas, por meio da EA, com enfoque no setor do agronegócio, considerando sua relevância político-econômica no cenário nacional, diante do cenário de difusão dos pressupostos neoliberais na educação escolar. Ao final, ainda trazemos algumas considerações relevantes sobre o papel do professor no enfrentamento desse cenário.

\section{DAS BASES À CONCEPÇÃO NEOLIBERAL: REFLEXÕES INTRODUTÓRIAS}

De acordo com o glossário ${ }^{1}$ do grupo de pesquisa HISTEDBR (s/d), o neoliberalismo pode

${ }^{1}$ Disponível em: http://www.histedbr.fe.unicamp.br/navegando/glossario/verb_c_neoliberalismo1.htm. Acesso em: 
ser definido como uma doutrina inspirada no liberalismo econômico clássico. A título de contextualização, o liberalismo se caracteriza como um movimento surgido no século XVII, a partir da Revolução Gloriosa da Inglaterra, em 1688, atingindo seu ápice quase um século depois, com as revoluções Americana e Francesa, em 1766 e 1789, respectivamente.

Tinha como base os pensamentos de "[...] Locke, Montesquieu, Kant, Rousseau, Benjamin Franklin, David Ricardo, Jefferson, Bentham, Stuart Mill, Smith, Tocqueville e tantos outros que influenciaram e subverteram a História da Humanidade" (OLIVEIRA, 2004, p. 464). Em seu cerne estava a ascensão da nova classe (burguesia) que lutava contra a nobreza, buscando limitar os poderes do rei e, com isso, separar o Estado do restante da sociedade na tentativa de reduzir a intervenção estatal e garantir a ascensão da esfera privada. Deu-se início, então, ao discurso sobre a importância de um estado mínimo, o qual deveria pautar-se no "consentimento dos cidadãos, que teriam garantido direitos individuais, tais como: liberdade de pensamento, expressão e religião; [na] prevalência do Estado de Direito; [na] rejeição às lutas religiosas, prisões infundadas, torturas e penas cruéis" (idem, ibidem), coerente com o momento de reconfiguração política e econômica e de enfrentamento às diretrizes religiosas.

O início do século XX evidenciou a necessidade de ajustes no sistema. Como afirmam Pereira e Almeida:

Da Pax Britannica², o mundo presenciou o acirramento da disputa inter-capitalista entre as principais nações no final o século XIX, culminando na primeira Guerra Mundial. A dificuldade da manutenção do pleno emprego, e os desajustes macroeconômicos e políticos nacionais e internacionais do entreguerras antecederam, por sua vez, a maior crise econômica do capitalismo de toda a sua história, a crise de 1929. Após a Grande Depressão ainda sucedeu-se a Segunda Guerra Mundial. Assim, em menos de quarenta anos, a sociedade capitalista parecia estar fadada ao colapso (PEREIRA; ALMEIDA, 2010, p. 3).

O processo político e econômico em curso e os problemas mundiais balançaram os alicerces até mesmo das grandes economias. As mudanças exigidas foram marcadas pelas ideias do economista britânico John Maynard Keynes. Reformularam-se as diretrizes - agora keynesianas -, mas não abandonaram o modo de produção. $O$ capitalismo permaneceu, exigindo, na visão de Keynes, a revisão do "papel do Estado na economia, considerando necessário aliar a eficiência econômica à liberdade individual, com especial atenção à justiça social, [...] a fim de garantir a regulação econômica, investindo em empresas para garantir o pleno emprego" (OLIVEIRA, 2004, p. 465).

No entanto, suas concepções foram questionadas devido à ineficiência do Estado na elaboração de políticas sociais e ao aumento da dívida externa e da inflação. Foi o momento de revisitar as bases clássicas econômicas liberais, transformando-as no Neoliberalismo.

Apesar da preponderância do keynesianismo até meados de 1970, o neoliberalismo

27 dez. 2017.

${ }^{2}$ Expressão utilizada para descrever o período de paz sentido desde o fim das Guerras Napoleónicas que teve como consequência uma maior expansão do Império Britânico. 
tem como marco fundamental o ano de 1947, devido à organização da Sociedade Mont Pèlerin, que reuniu figuras intelectuais importantes, conservadoras, como economistas, cientistas políticos e filófosos, incluindo o austríaco Friedrich August von Hayek e Milton Friedman. Afirmavam-se contrários à concepção liberal de Keynes e às políticas dela consequentes, como o próprio Estado do Bem-Estar Social, considernando que o Estado impedia a competição, necessária à prosperidade (CHAUÍ, 1999).

Não sem sentido, o neoliberalismo tem como proponentes Hayek e Friedman. O primeiro publicou em 1946 o livro O Caminho da Servidão, considerado o marco do nascimento do neoliberalismo, afirmando "posição contrária ao planejamento econômico e ao coletivismo predominantes em vários países - como Alemanha, Itália e União Soviética" (LOMBARDI, 2016, p. 82), o que delineou o Mont Saint Pélérin no ano seguinte. Uma das premissas de Hayek se encontrava na retórica de que era impossível apreender a realidade em sua totalidade. Assim, se "o indivíduo é incapaz de abarcar a totalidade, o Estado, enquanto órgão que procura totalizar ações, está fadado ao fracasso e, para que atenda melhor os anseios dos indivíduos, sem privá-los da liberdade, deve ser mínimo, reduzido" (ARCE, 2001, p. 253). Coerentemente, para Hayek, "o mercado e a economia devem seguir este modelo, pois o livre mercado, assim como o indivíduo e seu direito à liberdade, são produtos espontâneos da civilização" (idem, ibidem).

Embora já tivesse uma obra publicada vinte anos antes, Capitalismo e Liberdade, foi com sua segunda obra, Liberdade de Escolher, que Friedman alcançou êxito, em 1980. Conforme afirma Gentili (1996), o próprio autor evidencia que o sucesso que alcançou se atrelava à existência de um programa televisivo com o mesmo nome do livro - Liberdade de Escolher -, além de que "a opinião pública havia mudado" (idem, p. 3) e "as pessoas estavam mais receptivas à prédica insistente dos defensores do livre-mercado; [...] estavam alertas para se defenderem da voracidade de um Estado disposto a monopolizar tudo, inclusive o bem mais apreciado pelo ser humano, a liberdade individual" (idem, ibidem).

Ambos, Hayek e Friedman proferiam a livre competição e apenas a regulação do próprio mercado, com especial ênfase a privatização de diversos setores sociais e diminuição de direitos sociais. Para essa doutrina, o problema do capitalismo se encontrava no Estado, e não no próprio sistema, ou seja, era entendido como uma crise parcial.

Historicamente, a expansão do neoliberalismo pelos principais países capitalistas fez-se coerente. Os anos 1970 já contavam com a adesão ao sistema por Pinochet, no Chile, seguido nas próximas décadas por Margaret Thatcher, na Inglaterra, e Ronald Reagan, nos EUA. Foi um momento muito propício para se rebater a intervenção estatal, já que o mundo tinha se visto refém de regimes totalitários como os de Hitler, Mussolini e Stalin. A prerrogativa de que esses governantes representavam o "perigo eminente" do poder estatal às civilizações foi essencial:

Será no contexto da intensa e progressiva crise estrutural do regime de acumulação fordista que a retórica neoliberal ganhará espaço político e também, é claro, densidade ideológica. Tal contexto oferecerá a oportunidade necessária para que se produza esta confluência histórica entre um pensamento vigoroso no plano filosófico e econômico (embora, até então, de escasso impacto tanto aca- 
dêmico quanto social) e a necessidade política do bloco dominante de fazer frente ao desmoronamento da fórmula keynesiana cristalizada nos Estados de Bem-estar. A intersecção de ambas as dinâmicas permite compreender a força hegemônica do neoliberalismo (GENTILI, 1996, p. 3).

À manutenção do sistema capitalista nos mais variados países, com graus de desenvolvimento tão discrepantes, foi necessário que as ideias neoliberais extrapolassem a esfera econômica, como veremos a seguir.

\section{NeOliberalismo e EDUCAÇÃo}

Como afirmam Almeida e Damasceno (2015, p. 41), a crise de 1973 "marca a ruptura com a velha ordem assistencialista-keinesiana e a imperativa necessidade, para o capital, de instituir um novo modelo de acumulação", delineado nas ideias neoliberais. A concepção de falência do Welfare State não foi enterrada com a "velha ordem"; ao invés disso continuou a ecoar com implicações desastrosas na esfera social, mas devidamente importantes para manter a legitimação do capital e a tentativa de superação de sua crise (estrutural).

Oliveira (2004, p. 462) relembra que, a partir de 1980, com a expansão do processo de globalização próprio do neoliberalismo, os países latino-americanos se tornaram "laboratório de aplicação do novo modelo econômico imposto pelos países desenvolvidos, devido ao grande déficit público, aos altos índices inflacionários e à estagnação geral das empresas controladas pelo Estado". Corroborando, Lamosa indica que:

A década de 1980 representou um período de tormenta para a classe dominante brasileira, tanto em termos econômicos, quanto em termos políticos. Os termos econômicos foram sempre os mais noticiados e aparentes na crise que percorreu todos os países do capitalismo periférico e, destacadamente, os países da América Latina, decorrente do aumento dos juros no fim da década de 1970 (LAMOSA, 2014a, p. 75).

No cenário latino-americano ficou mais expressiva a complexidade do neoliberalismo que, além de um sistema econômico, instituiu um conjunto de ações e diretrizes no plano político, jurídico e educacional, colocando o mercado como o centro das decisões educacionais, de tal forma que "a escola, enquanto instituição social, passa a ser pensada como uma empresa produtiva e é com essa concepção que são planejadas as estratégias que direcionam as políticas educacionais" (ALMEIDA; DAMASCENO, 2015, p. 41).

Um dos representativos episódios que marcaram essa reformulação na educação aliada aos preceitos neoliberais foi o Consenso de Washington. Nele definiu-se:

[...] o receituário a ser aplicado nas economias dos países capitalistas, com especial preocupação para os países da periferia, destacadamente os latino-americanos, em crise pelo menos desde 1982 . As concepções da reunião foram assim definidas: 1 . Redução dos gastos públicos; 2 . Abertura comercial com a eliminação das barreiras alfandegárias; 3 . Abertura das economias ao capital estrangeiro; 4. Desregulamentação dos mercados domésticos, através da eliminação da intervenção do Estado, como controle de preços, incentivos, etc; 5 . Privatização das empresas e dos serviços públicos. Além do 
incentivo à inserção subordinada à economia mundial (LAMOSA, 2014a, p. 77).

A intervenção de mecanismos como o Fundo Monetário Internacional (FMI) e o Banco Mundial, em especial na América Latina, foi facilitada pela subserviência do governo brasileiro à economia mundial, repercutindo decisivamente na educação (ANDRIOLI, 2017) desde a ditadura militar. Foram colocadas como tarefas à educação dos países latinoamericanos, em conformidade aos pressupostos neoliberais, o processo educativo como gerador de trabalho, consumo e "cidadania", além de meio para estabilidade política, já que a educação é que garantiria governabilidade (ANDRIOLI, 2017). De maneira mais específica, Torres aponta os direcionamentos dados pelo Banco Mundial a partir de 1990:

a) prioridade da educação básica: b) melhoria da qualidade (eficiência) da educação: c) prioridade dos aspectos financeiros e administrativos da reforma educativa: d) descentralização e instituições escolares autônomas e responsáveis por seus resultados; e) participação dos pais e das comunidades nos assuntos escolares; f) impulso do setor privado e ongs como agentes educativos: g) mobilização e alocação eficaz de recursos adicionais para a educação de primeiro grau h) enfoque setorial na educação; i) definição de políticas e prioridades baseadas na análise econômica (TORRES, 1996, p. 131, grifos nossos).

Essa mesma década no Brasil, com o início do governo de Fernando Henrique Cardoso (PSDB), foi marcada por reformas gerenciais no Estado, tanto na área econômica "conduzida pela equipe de economistas reunidos desde o fim da década de 1970 no Programa de Pós-Graduação em Economia da PUC_RJ" (LAMOSA, 2014a, p. 75-76), quanto no Ministério da Educação e Cultura (MEC), que com uma "equipe de consultores do Banco Mundial, liderados por Paulo Renato, foram responsáveis por um período intenso de reformas legal, curricular e político-pedagógica da Educação Básica" (idem, ibidem).

Naquele momento, também passamos a propagar o discuso sobre a necessidade de educação para se alcançar equidade social. Mas, como, diante de um Estado "fragilizado" em que se evidenciavam tantos problemas educacionais?

A educação, apesar de ser responsabilidade pública, deixou de ser, obrigatoriamente, estatal (FALLEIROS et al., 2010). Isso abriu possibilidades para a participação de instituições públicas, privadas, população civil e qualquer um que tivesse algum propósito em prol da educação. Para Janke (2012, p. 46) "[o Estado] toma uma aparência impessoal, de uma dominação sem personificação, já que pela sua perspectiva democrática e, portanto, da instituição de um pacto, representa, enquanto instituição social democrática, a vontade popular, de todos".

A "Conferência Mundial Sobre Educação Para Todos", realizada em Jomtien, Tailândia, em 1990, e as diversas reuniões organizadas pela Unesco, como a que resultou no Relatório "Educação, um tesouro a descobrir", configuraram de maneira relavante as reformas educacionais no Brasil (GALVANIN, 2005). Na declaração gerada na Conferência tivemos, no sétimo artigo, a indicação da necessidade de alianças entre as autoridades responsáveis pela educação nos níveis nacional, estadual e municipal, incluindo os órgãos de planejamento, finanças, trabalho, comunicações, e outros setores sociais, como as organizações 
governamentais e não-governamentais, o setor privado, as comunidades locais, os grupos religiosos e as famílias (DECLARAÇÃO, 1990). Ao estabelecer algumas diretrizes para um plano de ação enfatizou que:

Se, mais uma vez, a educação básica for considerada como responsabilidade de toda a sociedade, muitos parceiros deverão unir-se às autoridades educacionais, aos educadores e a outros trabalhadores da área educacional, para o seu desenvolvimento. Isso implica que uma ampla gama de colaboradores - famílias, professores, comunidades, empresas privadas (inclusive as da área de informação e comunicação), organizações governamentais e não-governamentais, instituições, etc. - participe ativamente na planificação, gestão e avaliação das inúmeras formas assumidas pela educação básica (DECLARAÇÃO, 1990, grifos nossos).

A "educação para todos" exige, nessa perspectiva, que "todos" atuem nela. No entanto, é importante destacarmos que a educação escolar não se coloca como uma cumpridora de todas e quaisquer atividades, oriundas de qualquer agente ou instituição, como se a simples ação e boa vontade valessem por si. A educação escolar pressupõe fundamentos filosófico-pedagógicos e, sobretudo, planejamento para a ação educativa. A soberania participativa na educação, então, explicita mais do que uma "preocupação-atuação comum", mas uma estratégia.

No Brasil essa colaboração foi incentivada de inúmeras maneiras. O ideário da necessidade de reconfiguração da esfera econômica, por meio da redução dos gastos públicos, regulação da balança econômica nacional e manutenção da ideologia do capital, incidiu no campo educacional, distanciando o Estado das responsabilidades educacionais inerentes ao poder público. Na perspectiva da estratégia de colaboração, a educação foi uma das instâncias que recebeu atenção de membros da sociedade e, nessa reorganização do Estado brasileiro unido às esferas privadas, proporcionou aos empreendedores a possibilidade de se inserirem em espaços que antes eram ocupados, exclusivamente, pelo setor público.

Segundo Falleiros et al. (2010), a classe dirigente hegemônica apontou a necessidade de uma formação educativa e política para a construção de uma camada intelectual diferente das estabelecidas até então. Tivemos o surgimento do Pensamento Nacional das Bases Empresariais (PNBE), do Fórum Mundial organizado pelo BNDES e da Associação Brasileira de Empresários para a Cidadania (CIVES) (MENDES, 2015). Antes disso, ocorreu a criação do Instituto Liberal que "não representou uma única fração da classe dominante, mas serviu como aparelho organizador e difusor do programa neoliberal no Brasil, propondo políticas econômicas e sociais" (LAMOSA, 2014a, p. 77), por disseminar valores morais entre professores, advogados, jornalistas, universitários e magistrados.

Esse contexto contraditório alavancou, no Brasil, o surgimento da Terceira Via, um projeto político que, segundo Martins e Neves (2010, p. 119), se baseia "nos valores clássicos do liberalismo: liberdade, igualdade e fraternidade", agora ressignificados. A liberdade de antes passa a ser defendida, agora, pelo individualismo. A junção dos individuais passa a integrar todos, convergindo à fraternidade. Na defesa do princípio de igualdade, legitimase as diferentes culturas, ainda que negando a existência de classes sociais e suas contradições (MENDES, 2015). 
Sinteticamente, o projeto da Terceira Via sinaliza a importância de uma sociedade civil ativa, sob uma atmosfera solidária e permeada pelas subjetividades, difundindo que distintos atores sociais e organizações - públicas e privadas - "teriam criado novas referências de vida, diferentes daquelas vividas pelas gerações anteriores" (MARTINS; NEVES, 2010, p. 129), assim exaurindo a materialidade e a historicidade do enredo social (MENDES, 2015). Aponta para a urgência de mudança da sociedade civil, deixando de lado os debates sobre a exploração do trabalho, por meio da perversidade da lógica do capital em defesa da integração social, mas mantem "os fundamentos do capitalismo neoliberal, acrescidos de medidas paliativas para minorar as condições miseráveis de vida de grande parte da população mundial e [...] garantir a 'paz social'” (NEVES, 2011, p. 237).

Um evento que caracterizou o que esboçamos até aqui foi o congresso "Ações de Responsabilidade Social em Educação: Melhores práticas na América Latina”, iniciado por Fernando Haddad e organizado por três grupos empresariais - o Instituto Gerdau e as Fundações Jacobs e Coleman - tendo ocorrido em Salvador, em 2006. Naquele evento se reestruturou a ideia inicial de "educação para todos", surgindo o novo slogan e projeto "todos pela educação". Leher (2010, p. 4) afirma que os empresários visavam "indivíduos e organizações de caráter neofilantrópico" que manejariam a educação para que ela naturalizesse "as profundas desigualdades de classe e o desemprego estrutural, a expropriação e a hiperexploração" (idem, ibidem).

Nesse sentido, nos vimos diante de uma reformulada roupagem do padrão políticoeconômico na esfera global, na tentativa de implantar um modelo de sociabilidade do capital (LAMOSA, 2010), baseado na prestação de serviços dissociada de lutas sociais (MENDES, 2015). Na educação, difundiu-se o ideário de grandes grupos representantes da hegemonia brasileira, pautados numa suposta neutralidade que se justificava pelo diálogo entre diferentes instituições, como se a "troca de experiências" pudessem, por si só, resolver os problemas sociais e educacionais.

Sabemos que essa discussão não se encerre aqui, mas considerando os limites desse texto, apontamos agora a reflexão sobre as assertivas neoliberais no campo da Educação Ambiental escolar pelo exemplo da inserção da Associação Brasileira do Agronegócio (ABAG) e suas parceiras com as escolas públicas.

\section{AS RELAÇÕES PÚBLICO-PRIVADAS NA EDUCAÇÃO AMBIENTAL COMO IMPLICAÇÕES DO NEOLI- BERALISMO: O CASO DA ABAG}

A reorganização do mercado e a incisiva adequação do Estado à conjuntura neoliberal adentraram, então, os muros da escola, tendo os debates ambientais como prerrogativa facilitadora. Isso pode ser visualizado pela adoção, por parte do empresariado, da questão ambiental como possibilidade de se inserir no ambiente escolar e difundir sua suporta "responsabilidade socioambiental".

O discurso colaborativo, atrelado à necessidade de ações condizentes com o Desenvolvimento Sustentável, impulsionou a responsabilidade cidadã das empresas, resultando no surgimento de instituições como o Grupo de Institutos, Fundações e Empresas (Gife) e o 
Instituto Ethos. Esse último foi criado em 1998 e teve, desde então, grande relevância na disseminação do discurso social dentro do cenário neoliberal. Um dos exemplos disso é o número de empresas associadas (500 empresas) (ETHOS, 2018), além de parceiros institucionais. Antes, seu slogan "Associe-se ao Instituto Ethos: Contribua para o desenvolvimento Sustentável e prepare sua empresa para uma nova economia" (MENDES, 2015) era condizente com o momento inicial de sua atuação. Na atualidade, destaca que associar-se a ele é uma vantagem, pois "a empresa fará parte da maior rede de empresas para o desenvolvimento sustentável da América Latina, com mais de 500 associados, e terá a oportunidade de ser protagonista nos temas de sustentabilidade, antecipando riscos e desenvolvendo sua cadeia de valor" (ETHOS, 2018).

Sobre esses grupos e instituitos, Adrião $(2018$, p. 19) afirma que se constituem como um "[...] movimento, que articula braços sociais de grupos empresariais a retornos financeiros para estes mesmos grupos" e que "não é restrito ao Brasil e tem sido estimulado pela rede netFWD, vinculada ao Centro de Desenvolvimento da própria OCDE e integrada por um pequeno grupo de fundações, as quais, em um cenário de restrição dos fundos públicos nos países pobres e em desenvolvimento" (idem, ibidem).

No que concerne à EA temos, na Política Nacional de Educação Ambiental (PNEA), instituída pela Lei 9.795/99, em seu artigo 3o, o explícito direito à EA estendido a todos, cabendo ao "Poder Público, nos termos dos arts. 205 e 225 da Constituição Federal, definir políticas públicas que incorporem a dimensão ambiental, promover a educação ambiental em todos os níveis de ensino e o engajamento da sociedade na conservação, recuperação e melhoria do meio ambiente" (BRASIL, 1999).

No entanto, mesmo na PNEA existem facilitações explícitas à entrada de diversas instituições no contexto educacional público. Em sua Sessão III, que compete a Educação Ambiental Não-Formal, indica em seu artigo 13ㅇq que "Entendem-se por educação ambiental não-formal as ações e práticas educativas voltadas à sensibilização da coletividade sobre as questões ambientais e à sua organização e participação na defesa da qualidade do meio ambiente"; porém, no inciso III do mesmo artigo relaciona tais ações às escolas (colocadas de forma ampla, sem direcionamento especifico às públicas ou privadas), afirmando incentivar "a participação de empresas públicas e privadas no desenvolvimento de programas de educação ambiental em parceria com a escola, a universidade e as organizações nãogovernamentais" (grifos nossos).

Loureiro e Lima (2012) apontam como, desde a década de 1990, os setores empresariais perceberam na EA uma estratégia eficaz para se inserirem no meio educacional, com respaldo da PNEA. Na realidade, o discurso de colaboração à educação e de preocupação ambiental foi algo necessário ao setor privado, já que as mudanças no mercado passaram a prezar pelo marketing verde e pela inserção do empresariado no escopo mundial de responsabilidade socioambiental. Um exemplo claro disso foi a procura por certificações ambientais, tais como a ISO NBR 14.001, adotadas de forma crescente no Brasil. A EA passou a ser, então, um caminho extremamente favorável para que as instituições dos setores privados de grande relevância econômica no Brasil se inserissem nas escolas públicas, já que para determinadas certificações são consideradas resquisitos as ações de EA, podendo ser 
desenvolvidas tanto no próprio meio empresarial, como em outras instâncias sociais.

Sabemos que o campo educacional é permeado por entraves e que pode se estabelecer como perpetuador da manutenção da ordem social ou como catalisador de transformações sociais, não por si só, mas pela atuação de seus agentes. Da mesma forma, os pontos legais acima destacados servem como premissa à entrada facilitada de empresas e organizações de caráter privado nas escolas públicas, denotando tais ações como legítimas e difundindo seu caráter positivo, pautado na lógica neoliberal (MENDES, 2015).

Como um exemplo dessa inserção e de algumas consequências diretas e indiretas à educação pública temos o Programa Educacional "Agronegócio na Escola”, desenvolvido pela Associação Brasileira do Agronegócio (ABAG) na região de Ribeirão Preto, interior de São Paulo, mediante parceria com as Secretaria Municipais de Educação (SMEs) ${ }^{3}$.

Conforme investigado por Mendes e Lamosa (2015, p. 2), a "representatividade da ABAG no cenário nacional e internacional é de grande abrangência e relevância, especialmente para a difusão da importância do agronegócio para a vida das pessoas e de sua responsabilidade ambiental".

A fundação da ABAG ocorreu em 1993 e sua apresentação oficial foi feita ao Congresso Nacional pelo seu presidente, Ney Bittencourt de Araújo (MENDES, 2015). Lamosa (2013) afirma que a ABAG teve suas origens atreladas ao momento em que a Organização das Cooperativas Brasileiras (OCB) ganhou visibilidade no cenário nacional. A OCB foi presidida - até o momento de fundação da ABAG - por Roberto Rodrigues que, junto a Ney Bittencourt, foi quem orquestrou a criação da referida associação.

Ainda que não seja foco discutir detalhadamente o surgimento da ABAG, destacamos que a aliança entre a ABAG e a OCB representa, até os dias de hoje, a força hegemônica do patronato rural (MENDONÇA, 2008). No seu início, a ABAG também firmou aliança com a Sociedade Nacional da Agricultura (SNA), oriunda do Rio de Janeiro, e com a Sociedade Rural Brasileira (SRB), originalmente paulista. O que nos chama à atenção é que mesmo disputando a hegemonia do setor durante décadas, as duas entidades estiveram atreladas, a partir da década de 1990, a esse novo tipo de associação, a ABAG:

A maneira como se deu a criação e a formação da ABAG elucida os embates políticos e econômicos que permeiam a inserção da mesma nas escolas públicas, representando para esta uma relevante oportunidade de alcançar -direta ou indiretamente - a população como um todo e, consequentemente, de manter a hegemonia do patronato rural. A associação conseguiu reunir diferentes frações da sociedade, se configurando como um novo tipo de organização, em parceria com setores industriais, financeiros, comerciais e até com instituições de nível superior, de grande importância para a produção de conhecimento científico (MENDES; TALAMONI, 2017, p. 79).

Atualmente, a ABAG é composta por diversos segmentos do agronegócio e seus representantes empresariais, além de integrar fundos consultivos e administrativos, conselhos,

\footnotetext{
${ }^{3}$ Antes as parcerias eram feitas com as Diretorias de Ensino, mas devido às dificuldades materiais e organizacionais encontradas para execução do Programa, a ABAG optou por definir suas parcerias na instância Municipal, com apoio inicial da Secretaria Municipal de Educação de Ribeirão Preto (MENDES, 2015).
} 
câmaras setoriais e comissões. Como exemplos, podemos citar a CONSAGRO (Conselho do Agronegócio vinculado ao Ministério da Agricultura), CODEAGRO (Coordenadoria de Desenvolvimento dos Agronegócios), Conselho Superior do Agronegócio da Federação das Indústrias do Estado de São Paulo (Fiesp/Cosag); Conselho Nacional de Política Agrícola (MAPA/CNPA); Conselho Assessor Nacional da Empresa Brasileira de Agropecuária (Embrapa); Conselho Superior de Estudos Avançados (Fiesp/Consea); Conselho Nacional de Segurança Alimentar (Planalto/Consea); Conselho Estadual de Segurança Alimentar e Nutricional Sustentável (Consea); Conselho Diretor do InpEV; Conselho Nacional da Pecuária de Corte; Conselho Curador da Fealq; Conselho Consultivo da Agrishow; Conselho Superior de Estudos Avançados; Comissões como Mista Brasil-Alemanha para o Agronegócio; Nacional Pública-Privada Assessora - COPAS (Política Governamental para Alimentos Seguros) - Secretaria de Desenvolvimento Agropecuária e Cooperativismo (MAPA/SDA); De Agroindústria - CNI; Comitê do Agronegócio da BM\&F Bovespa e Comitê Gestor do Fundo Setorial do CMT Nacional de Integração Lavoura-Pecuária - Secretaria de Desenvolvimento Agropecuária e Cooperativismo (MAPA/SDA) (ABAG, 2014). A lista não se encerra aqui; poderíamos incluir entre seus parceiros bancos como o Itaú, Santander, Caixa Econômica Federal e Banco do Brasil, os meios de comunicação, como a Globo Comunicações, e multinacionais - envolvidas em diversas controvérsias sociambientais - como a Nestlé, a Monsanto, a Syngenta, Cargil e a Vale (ABAG, 2018). Notamos, pelo pouco descrito que:

[...] a nova organização [ABAG] não é um tipo tradicional de representação patronal, ou seja, não fala apenas em nome de uma fração agrária. A nova associação mobiliza entre seus associados um conjunto de frações agrárias e outras que historicamente estiveram associadas à urbanidade, no caso das frações industriais e financeiras. O objetivo do partido do agronegócio foi formular e mobilizar, difundindo os interesses do conjunto das frações agrárias mais modernas do Brasil, além da unidade entre estas e outras frações da classe dominante (LAMOSA, 2013, p. 3).

A ABAG possui, entre suas filiais, a ABAG Ribeirão Preto (ABAG/RP), criada por iniciativa de diversas lideranças do agronegócio na região, historicamente importantes para o desenvolvimento do setor e compostas por empresários das variadas cadeias produtivas. Em 2001, a ABAG/RP iniciou sua inserção nas escolas públicas de Ribeirão Preto e de cidades do entorno por meio do Programa Educacional "Agronegócio na Escola" que, de acordo com a própria instituição, tem como objetivo difundir seus interesses e valorizar a imagem do agronegócio na região (MENDES, 2015). Conforme explicita a autora (p. 149), "No site oficial da ABAG é possível encontrar apontamentos relativos à "responsabilidade social" e ao compromisso com a "sustentabilidade", cujas ações ficam sob os cuidados do setor Agronegócio Responsável (ARES)", que "vem sendo, desde 2007, responsável por organizar a assistência às frações agroindustriais diante das exigências contemporâneas associadas à "sustentabilidade" e à "responsabilidade social" das empresas" (LAMOSA, 2014a, p. 25). Nesse sentido, o objetivo central da ABAG, com o Programa "Agronegócio na Escola", é difundir uma imagem favorável do agronegócio na região, pautando-se na sua "responsabilidade socioambiental".

O site oficial da ABAG descreve que o Programa "trabalha temas relativos ao Agronegó- 
cio com professores, coordenadores e alunos das duas últimas séries do ensino fundamental, jovens na faixa etária de 13 a 14 anos de idade" (ABAG/RP, 2014). Destaca, entre seus objetivos:

[...] levar conceitos fundamentais do agronegócio aos alunos e, através de visitas às empresas associadas, possibilitar a conexão entre teoria e prática, levando a realidade do setor e da região para a sala de aula, e vice-versa. Revelar assim a interdependência campo-cidade, a dimensão e a importância do setor para a economia, valorizar as atividades agroindustriais locais e com isso, a comunidade onde o aluno está inserido, e resgatar o orgulho de pertencer a esta região (ABAG/RP, 2014 apud MENDES, 2015, p.150).

O Programa possui uma metodologia própria, incluindo a capacitação de professores e coordenadores pedagógicos das escolas envolvidas, distribuição gratuita de materiais destinados aos alunos e professores, e a participação em concursos de desenhos e de redações "que relatem, através da perspectiva construída pelos alunos sobre o agronegócio, a ideia de valor, importância e dependência irrefutável da população ao setor" (MENDES, 2015 , p. 150). Apesar de se tratar de um programa educacional, sua elaboração não envolveu a participação de agentes educacionais ou profissionais da área pedagógica, partindo dos próprios dirigentes da ABAG (MENDES, 2015).

São oferecidas também palestras e a realização de visitas às empresas associadas à ABAG, vinculadas ao setor do agronegócio, que constituem etapa essencial ao programa já que, como exposto no site da associação, "Somente após essa fase é que os professores desenvolvem o tema de forma interdisciplinar com seus alunos, ao longo do ano letivo. Os alunos também têm a oportunidade de ver de perto o agronegócio: roteiros especiais de visitas são oferecidos para todas as escolas" (ABAG/RP, 2014 apud MENDES, 2015, p.150). O tema mencionado diz respeito ao aspecto que, envolvendo o agronegócio (temática), norteará as atividades a serem realizadas por professores e alunos, nas escolas, durante a participação deles no Programa.

Após todas as ações estipuladas na metodologia, os professores devem enviar o relatório final das atividades desenvolvidas (incluindo o projeto feito na escola), o que culminará na atribuição do "prêmio professor", ou seja, a premiação dos melhores projetos desenvolvidos pelos professores.

Há diversos outros aspectos referentes ao Programa e à atuação da ABAG no meio educacional ${ }^{4}$, mas o ponto central está na difusão da ideologia atrelada ao agronegócio - especialmente em seu viés empresarial -, reforçando a importância do setor (segundo a visão da $A B A G / R P)$ à população e exigindo que professores e alunos a reproduzam nas atividades. Não obstante, a mídia avigora tal compreensão e, principalmente, a ideologia, ao divulgar vídeos interinstitucionais sobre o agronegócio:

Como estratégia para contribuir para eliminar os "pré-conceitos" ligados ao setor, nas novas peças publicitárias a palavra Agronegócio ganhou contornos diferentes: AgroTrabalho, AgroSaúde, AgroVi-

\footnotetext{
${ }^{4}$ Ver detalhes em Mendes (2015) e Lamosa (2014a).
} 
da, AgroEnergia e AgroFuturo. A substituição do termo "negócio" por outros que permeiam o dia a dia das pessoas serviu para mostrar o quanto o agronegócio está presente em suas vidas, sem que elas se deem conta disso (ABAG/RP, 2014 apud MENDES, 2015, p.151).

O alcance do Programa tem sido extremamente significativo devido à dimensão espaçotemporal (existente há 17 anos, envolvendo, até 2013, 38 municípios da região de Ribeirão Preto, 102 escolas e 14161 estudantes). Notamos, com isso, que o objetivo geral tem sido atingido, mas não somente ele. Mendes (2015), em entrevistas com professores, observou que a parceria com a ABAG contitui-se como um incentivo essencial à inserção dos estudantes no ensino técnico agrícola assim que estes ingressam no Ensino Médio, logo após participarem do Programa (MENDES, 2015), como um meio de se colocarem-se no mercado de trabalho da região. Corroborando, Lamosa (2014a) afirma que:

[...] O mais importante deles [dos efeitos gerados] é o aproveitamento de alunos das escolas públicas como mão de obra para as empresas associadas. Apesar deste não ser um objetivo declarado do programa foi possível verificar que todos os entrevistados até o momento afirmaram como um dos pontos positivos do programa criar entre os alunos um estímulo a pensar sua inserção no mercado de trabalho (LAMOSA, 2014a, p. 189).

Levando em consideração os dados de Mendes (2015) e Lamosa (2014a), a aceitação das parceiras público-privadas entre a ABAG (e suas empresas afiliadas) e as escolas públicas, é praticamente ${ }^{5}$ unânime. Como as parcerias são feitas, primeiramente, entre a ABAG e as SMEs, para que então a primeira possa adentrar as escolas, percebemos que a própria instância educacional pública (SME), em alguns casos, se isenta da responsabilidade de analisar as ações que chegarão às escolas, incluindo os aspectos pedagógicos e ideológicos que as sustentam; e, em outros, coadunam com a posição da ABAG quanto aos aspectos estritamente favoráveis do setor do agronegócio à população e a importância do empresariado nas escolas públicas, reafirmando o os preceitos neoliberais. Perde-se, assim, o real papel da educação escolar - comprometimento com a formação intelectual e crítica dos estudantes - e reforça-se a função de adequação dos indivíduos à sociedade que está posta.

Mendes (2015) afirma que no site da ABAG e no próprio discurso da representante da associação, vinculada à execução do Programa Educacional, em entrevista realizada, não há menção direta à EA nas ações do Programa. No entanto, esses dados chamam a atenção por dois motivos: mesmo sem afirmar sua vinculação à EA, utiliza-se da responsabilidade socioambiental e de temáticas relacionadas à problemática ambiental para configurar sua inserção nas escolas públicas da região, através de ações educativas; ao mesmo tempo, professores e secretários e/ou representantes das SMEs entrevistados por Mendes (2015) compreendem que o Programa e suas atividades são de educação ambiental (MENDES; TALAMONI, 2017). A contradição é evidente, pois mesmo com a ABAG não afirmando executar ações de EA, os professores - que estão entre os principais agentes edu-

\footnotetext{
${ }^{5}$ Lamosa (2014a) encontrou resistência, no momento de sua pesquisa, apenas no município de Matão-SP.
} 
cacionais envolvidos no processo educativo e na participação do Programa - as entendem como tal e, portanto, aceitam o Programa da ABAG como sendo de EA.

A EA, revestida como responsabilidade socioambiental empresarial e de setores correlatos, serve ao propósito de reprodução do discurso dominante sobre o agronegócio e retira do debate suas implicações ao meio socioambiental, reforçando a disseminação da ideologia do setor a serviço do capital dentro das escolas públicas da região. Nesse sentido, o Programa se constitui como uma forma de privatização do ensino, ainda que no âmbito ideológico, mas com consequências práticas evidentes (MENDES, 2015). Um estudo recente realizado por Adrião (2018) sobre as dimensões e formas de privatização da educação brasileira corrobora nossa afirmação. Esse processo pode ser dar por diferentes vias, como na gestão escolar, na oferta educacional e no currículo. O caso da ABAG analisado por nós se relaciona à última, pois para a autora:

A privatização do currículo não se refere apenas aos tradicionais processos de compra de insumos e materiais necessários ao ensino [...]. Trata-se, mais amplamente, da transferência para o setor privado da definição do que ensinar, do como ensinar e do quando ensinar, além dos processos de verificação da aprendizagem, ou seja, da definição dos desenhos curriculares (ADRIÃO, 2018, p. 20).

Nesse sentido, o Programa da ABAG apresenta-se como um reflexo dos pressupostos neoliberais da sociedade atual, primeiramente por reforçar o marketing verde empresarial, que como já foi amplamente discutido na literatura, consolida as adequações pontuais do modelo capitalista as demandas reais e concretas da sociedade, sem de fato se comprometer com elas; e, concomitantemente, por se viabilizar as parcerias público-privadas entre setores estratégicos, social, cultural e economicamente, como o agronegócio e a educação escolar, interferindo no planejamento e desenvolvimento do processo educativo.

Com a intenção de apontar delineamentos finais, nos debruçamos brevemente na análise do papel do professor nesse cenário. Não estamos caindo numa armadilha ingênua que credita o sucesso (ou fracasso) educacional ao professor; sabemos que a transformação social não se encerra no trabalho docente comprometido, tão pouco na educação escolar, mas defendemos a importância da mediação do professor na formação de indivíduos críticos e atuantes no tecido social.

A inserção da ABAG nas escolas não ocorre diretamente pela autorização do professor, no entanto, sua participação é vital para a execução do Programa, pois exige o comprometimento dele para desenvolver, com os alunos, as atividades propostas e é ele o premiado. Isso não acontece por acaso. Conforme afirma Lamosa (2014b, p. 2), "os docentes, diferente dos intelectuais orgânicos que ocupam o posto de direção política da associação, cumprem o papel de difundir na realidade local a auto imagem do agronegócio", introduzindo "no seio da classe trabalhadora, neste caso, através da educação de seus filhos, a ideologia da classe dominante" (idem, ibidem).

As ações propostas pelo Programa da ABAG impossibilitam e negam a concepção crítica sobre a problemática socioambiental e sua relação com a totalidade social que deveriam integrar a prática social dos estudantes e professores, ponto de partida e de chegada do 
processo educativo (SAVIANI, 2010). Ainda assim, ao considerarmos a realidade como intrinsicamente contraditória e que precisa ser apreendida como uma síntese de múltiplas determinações, o sucesso alcançado pela ABAG é passível de ser enfrentado, assim como tantas outras relações público-privadas no campo educacional.

A possibilidade de se contrapor a hegemonia do grupo dominante requer do intelectual orgânico romper com a sua posição tradicional, e dessa forma, criar mecanismos capazes de relacionar política e hegemonia da classe trabalhadora, contrapondo-se com a classe dominante [...]. Assim, existem duas maneiras de lidar com a formação de sua concepção do mundo. Ou o indivíduo participa de uma concepção do mundo imposta pelo ambiente exterior, por vários grupos sociais, nos quais todos estão envolvidos desde sua entrada no mundo consciente, ou elabora a própria concepção do mundo de uma maneira crítica e consciente e, portanto, em ligação com o próprio pensamento, escoIhendo a própria esfera de atividade, participando ativamente na produção histórica do mundo, sendo guia de si mesmo e não aceitando o exterior de forma passiva (VIEIRA, 2008, p. 157).

Em nosso entendimento, uma forma de enfrentamento (que precisa ser abordada em estudos futuros de forma aprofundada) está no trabalho docente comprometido e consciente sobre o contexto atual. Existem diversos estudos (TOZONI-REIS, 2013; SOUZA, 2014; MENDES et al., 2016) que evidenciam como os próprios professores não se sentem capacitados para atuarem em ações de EA ou as realizam de forma fragilizada e pontual, de tal maneira que a ação docente representa uma das limitações para que a EA seja desenvolvida na escola e pela escola. Para isso, é necessário que os professores tenham subsídios teóricos e práticos para desenvolverem as próprias ações no âmbito escolar, o que perpassa por uma formação inicial e contiuada que se alicerce nesse objetivo. Com isso, os docentes terão a opção consciente de recusar as parcerias público-privadas que intensificam e perpetuam incisivas neoliberais na educação pública.

\section{CONSIDERAÇÕES FINAIS}

O presente estudo buscou realizar uma leitura crítica sobre os pressupostos neoliberais que, assim como em outras esferas sociais, trazem implicações diretas à educação. Defendemos que o papel da educação escolar é o de possibilitar às classes trabalhadoras o acesso ao conhecimento sistematizado e, nesse sentido, não pode ser compreendida como um espaço para a realização de quaisquer ações, oriundas de agentes e instituições que não possuem, de fato, nenhuma intenção que coadune com esse papel. Ao contrário, tais ações pautam-se numa suposta colaboração neutra que, no seu cerne, reproduzem ideologias para valorizar os interesses do capital.

Nossa intenção foi a de evidenciar como instituições externas às escolas públicas, de caráter privado, encontraram na EA e na responsabilidade socioambiental uma estratégia favorável para se inserirem naqueles espaços. Exemplificamos tal situação, analisando a atuação da Associação Brasileira do Agronegócio (ABAG) na região de Ribeirão Preto, interior de São Paulo, por meio do Programa Educacional "Agronegócio na Escola". É inegável a relevância político-econômica e cultural do setor do agronegócio no cenário brasileiro e 
da representatividade da ABAG inserida em diferentes conselhos, comissões e com inúmeras empresas parceiras.

A discussão se concentrou nos motivos da inserção do setor privado nas escolas públicas pela EA em decorrência do neoliberalismo, caracterizando uma relação públicoprivada. Além disso, apontamos as interferências geradas por esse processo na educação escolar e, especificamente, na EA, já que ao reproduzir sua ideologia retira, dos estudantes, a possibilidade de uma formação crítica e de compreensão sobre as bases concretas da crise socioambiental.

Dentro dos limites desse texto, indicamos a estratégica ação do Programa "Agronegócio na Escola" da ABAG que, respaldada na ação do professor e na ilusória premiação a que este concorre, garante o desenvolvimento das atividades propostas. Consequentemente, sinalizamos a necessidade de enfrentamento de tal realidade, mediante o desenvolvimento de um trabalho docente comprometido e entendendo que ao professor devidamente instrumentalizado será facultada a compreensão do contexto das contundentes ações neoliberais no meio educacional e a possibilidade de desenvolver a EA crítica na escola.

\section{REFERÊNCIAS}

ABAG. Associação Brasileira do Agronegócio. 2018. Disponível em: <http://www.abag. com.br/institucional/associados>. Acesso em: 10 ago. 2018.

ABAG/RP. Associação Brasileira do Agronegócio da Região de Ribeirão Preto. 2014. Disponível em: <http://www.abagrp.org.br/ >. Acesso em: 4 fev. 2014.

ADRIÃO, Theresa. Dimensões e formas da privatização da educação no Brasil: caracterização a partir de mapeamento de produções nacionais e internacionais. Currículo sem fronteiras, v. 18, n. 1, p. 8-28, jan./abr. 2018.

ALMEIDA, Alberto Alexandre Lima; DAMASCENO, Maria Francinete. O neoliberalismo e a educação brasileira: a qualidade total em questão. Revista Educação, v. 10, n. 2, p. 40-46, 2015.

ANDRIOLI, Antônio Inácio. As políticas educacionais no contexto do Neoliberalismo. 2017. Disponível em: <http://www.andrioli.com.br/index.php/artigos/10-as-politicas-educaciona is-no-contexto-do-neoliberalismo>. Acesso em: 01 mai. 2018.

ARCE, Alessandra. Compre o kit neoliberal para a educação infantil e ganhe grátis os dez passos para se tornar um professor reflexivo. Educação \& Sociedade, ano XXII, n. 74, p. 251-283, abr. 2001.

BRASIL. Lei 9.795, de 27 de abril de 1999. Política Nacional de Educação Ambiental. Disponível em: <http://www.planalto.gov.br/ccivil_03/Leis/L9795.htm>. Acesso em: 15 abr. 2018.

CHAUÍ, Marilena. Ideologia neoliberal e universidade. In: OLIVEIRA, F.; PAOLI, M. C. Os sentidos da democracia: políticas do dissenso e hegemonia global. Petrópolis/Brasília: Vozes/Nedic, 1999.

DECLARAÇÃO. Declaração mundial sobre Educação para Todos. Plano de ação para satisfazer as necessidades básicas de aprendizagem. 1990. Disponível em: <http://www.direi toshumanos.usp.br/index.php/Direito-a-Educa\%C3\%A7\%C3\%A3o/declaracao-mundial-so 
bre-educacao-para-todos.html>. Acesso em: 18 abr. 2018.

ETHOS. Instituto Ethos. 2018. Disponível em: <http://www3.ethos.org.br/conteudo/asso ciados/associe-se/\#.VQB-EXzF91Z >. Acesso em: 12 jan. 2018.

FALLEIROS, lalê. et al. Fundamentos históricos da formação/atuação de seus intelectuais orgânicos. In: NEVES, L. M. W. Direita para o social e esquerda para o capital: intelectuais da nova pedagogia da hegemonia no Brasil. São Paulo: Xamã. 2010.

FIGUEIREDO, Pâmela B. et al. A relação público-privado a partir da educação ambiental. Em: XVI Encontro Paranaense de Educação Ambiental (EPEA) 2017, Curitiba-PR. Anais... 2017. Disponível em: <http://www.epea2017.ufpr.br/wp-content/uploads/2017/07/06-07fich\%C3\%A1rio.pdf>. Acesso em: 12 abr. 2018.

GALVANIN, Beatriz. Reforma do sistema educacional dos anos 90: breves considerações sobre os aspectos históricos, econômicos, e políticos. Hórus - Revista de Humanidades e Ciências Sociais Aplicadas, n. 03, p. 1-14, 2005.

GENTILI, Pablo. Neoliberalismo e educação: manual do usuário. 1996. Disponível em: <http://static.recantodasletras.com.br/arquivos/4002523.pdf >. Acesso em: 12 abr. 2018. JANKE, Nádia. Política nacional de educação ambiental: contradições e disputas. Tese (Doutorado em Educação para a Ciência). 2012. 232f. Programa de Pós-graduação em Educação para a Ciência, Faculdade de Ciências, UNESP, Bauru, 2012.

LAMOSA, Rodrigo Andrade da Cruz. A Educação Ambiental e o Novo Padrão De Sociabilidade Do Capital: um estudo nas escolas de Teresópolis (RJ). 2010. 168f. Dissertação (Mestrado em Educação). Faculdade de Educação da Universidade Federal do Rio de Janeiro, Rio de Janeiro, 2010.

LAMOSA, Rodrigo Andrade da Cruz; LOUREIRO, Carlos Frederico Bernardes. A educação ambiental e as políticas educacionais: um estudo nas escolas públicas de Teresópolis (RJ). Educação e Pesquisa, São Paulo, v. 37, n.2, p. 279-292, mai./ago. 2011.

LAMOSA, Rodrigo Andrade da Cruz. O programa Agronegócio na Escola: um estudo de caso sobre a educação ambiental empresarial nas escolas públicas brasileiras. Em: VII Encontro de Pesquisa em Educação Ambiental, EPEA, 2013, Rio Claro-SP. Anais... 2013. Disponível em: <http://www.epea.tmp.br/epea2013_anais/pdfs/plenary/0073-1.pdf.>. Acesso em: 19 fev. 2018.

LAMOSA, Rodrigo Andrade da Cruz. Estado, Classe social e Educação no Brasil: uma análise crítica da hegemonia da Associação Brasileira do Agronegócio. 2014. 436f. Tese (Doutorado em Educação). Faculdade de Educação da Universidade Federal do Rio de Janeiro, Rio de Janeiro, 2014a.

LAMOSA, Rodrigo Andrade da Cruz. A Hegemonia do Agronegócio: o capital vai à escola e forma seus novos intelectuais. Em: VI Encontro da Rede de Estudos Rurais, 2014, Campinas-SP. Anais... 2014b. Disponível em: <http://www.redesrurais.org.br/6encontro/traba Ihos/Trabalho_167.pdf>. Acesso em: 12 nov. 2014.

LAYRARGUES, Philippe Pomier; LIMA, Gustavo Ferreira da Costa. Mapeando as macrotendências político-pedagógicas da educação ambiental contemporânea no Brasil Em: VI Encontro "Pesquisa em Educação Ambiental", Ribeirão Preto, 2011, Anais..., 2011. CDROM. 
LEHER, Roberto. Neoliberalismo se apropria da idéia de "inclusão" para privatizar a educação. Jornal dos Sem Terra, n. 308, nov./dez. 2010.

LOMBARDI, José Claudinei. Crise do Capitalismo e Educação: algumas anotações. In: LOMBARDI, J. C. (org). Crise capitalista e Educação Brasileira. Uberlândia, BH: Navegando publicações, 2016. p. 61-93.

LOUREIRO, Carlos Frederico Bernardes. Trajetória e fundamentos da educação ambiental. São Paulo: Cortez, 2012.

LOUREIRO, Carlos Frederico Bernardes; LIMA, Maria Jacqueline Girão Soares de. A hegemonia do discurso empresarial de sustentabilidade nos projetos de educação ambiental no contexto escolar: nova estratégia do capital. Revista Contemporânea de Educação, v. 7, n. 14, p. 280-294, ago./dez. 2012.

MARTINS, Andre Silva; NEVES, Lúcia Maria Wanderley. Fundamentos teóricos da formação/atuação dos intelectuais da nova pedagogia da hegemonia. In: NEVES, L. M. W. Direita para o social e esquerda para o capital: intelectuais da nova pedagogia da hegemonia no Brasil. São Paulo: Xamã, 2010.

MENDES, Carolina Borghi. Influências de instituições externas à escola pública: privatização do ensino a partir da Educação Ambiental? 2015. 232f. Dissertação (Mestrado em Educação para a Ciência). Programa de Pós-graduação em Educação para a Ciência, Faculdade de Ciências, UNESP, Bauru, 2015.

MENDES, Carolina Borghi. et al. A inserção da educação ambiental nos cursos de formação de professores: transversalidade ou disciplinaridade? In: III Fórum de Educação Ambiental Crítica, 2016, Bauru. Anais... Bauru, 2016, p. 137-141.

MENDES, Carolina Borghi; TALAMONI, Jandira Liria Biscalquini. A privatização do ensino a partir da educação ambiental: reflexões sobre relações público-privadas. Revista Trabalho, Política e Sociedade, v. 2, n. 2, p. 65-82, jan./jun. 2017.

MENDES, Carolina Borghi; TALAMONI, Jandira Liria Biscalquini. Educação Ambiental Crítica e influências de instituições externas à escola pública: revisitando reflexões. In: Livro de Resumos do 43 Ciclo de Seminários em Ensino de Ciências, Matemática e Educação Ambiental, UNESP, Bauru. Anais... 2018. Disponível em: <http://wwwp.fc.unesp.br/\#!/ciclodese minariosprofnardi/anais/>. Acesso em: 01 mai. 2018.

MENDONÇA, Sônia Regina. O Patronato Rural Brasileiro na atualidade: dois estudos de caso. Anuario del Centro de Estudios Históricos Prof. Carlos S. A. Segreti, Córdoba (Argentina), año 8, n. 8, p.139-159, 2008.

MÉSZÁROS, Istevans. A educação para além do capital. São Paulo: Boitempo Editorial, 2008.

NEVES, Lúcia Maria Wanderley. Direita para o social e esquerda para o capital: intelectuais da nova pedagogia da hegemonia no Brasil. São Paulo: Xamã. 2010.

NEVES, Lúcia Maria Wanderley. A nova pedagogia da hegemonia no Brasil. Perspectiva, Florianópolis, v. 29, n. 1, p. 229-242, jan./jun, 2011.

NEVES, Lúcia Maria Wanderley. O professor como intelectual estratégico na disseminação da nova pedagogia da hegemonia. 36ạ Reunião Nacional da ANPEd, Goiânia-GO. Anais... 2013. Disponível em: <http://36reuniao.anped.org.br/pdfs_trabalhos_encomendados/ 
gt05_trabencomendado_lucianeves.pdf>. Acesso em: 20 abr. 2014.

OLIVEIRA, Maria José Galleno de Souza. A globalização da pobreza: impacto das políticas sociais do Estado Neoliberal nas democracias dos países latino-americanos. Revista da Faculdade de Direito da Universidade de São Paulo, v. 99, p. 461-474, 2004.

PANIAGO, Maria Cristina Soares. Keynesianismo, neoliberalismo e os antecedentes da "crise" do estado. s/d. Disponível em: http://www.cristinapaniago.com/yahoo_site_admin /assets/docs/Keynesianismo_Neoliberalismo_e_os_Antecedentes_da_Crise_do_Estado.18 5191109.pdf>. Acesso em: 20 abr. 2018.

PEREIRA, Leandro Ramos; ALMEIDA, Rodrigo Bonecini. A utopia keynesiana: os princípios políticos e econômicos de John Maynard Keynes. Em: 33a Reunião Anual da ANPEd, Caxambu-MG, 2010. Anais... 2010. Disponível em: <http://www.anpec.org.br/encontro2010/ inscricao/arquivos/247-5e5566e256850fa7bdd3a16da63d16a2_.pdf>. Acesso em: 06 abr. 2018.

SAVIANI, Dermeval. Pedagogia Histórico-Crítica: primeiras aproximações. 11 ed. Campinas, SP: Autores Associados, 2011.

SAVIANI, Dermeval. Escola e democracia. 34 ed. Campinas, SP: Autores Associados, 2012. SAVIANI, Dermeval. A crise estrutural do capitalismo e seus impactos na educação pública brasileira. In: LOMBARDI, J. C. (org). Crise capitalista e Educação Brasileira. Uberlândia, MG: Navegando publicações, 2016. p. 33-45.

SOUZA, Daniele Cristina. A Educação Ambiental Crítica e sua construção na escola pública: compreendendo contradições pelos caminhos da formação de professores. 2014. $324 \mathrm{f}$. Tese (Doutorado em Educação para a Ciência). Programa de Pós-graduação em Educação para a Ciência, Faculdade de Ciências, UNESP, Bauru, 2014.

TORRES, Rosa Maria. Melhorar a qualidade na educação básica? As estratégias do Banco Mundial. In: WARDE, M. J.; TOMMASI, L.; HADDAD, S. (orgs.). O Banco Mundial e as políticas educacionais. São Paulo: Cortez/PUC-SP, 1996, p. 125-194.

TOZONI-REIS, Marília de Freitas Campos. Princípios metodológicos da Educação Ambiental. In: Metodologias Aplicadas à Educação Ambiental. Curitiba, PR: IESDE, 2012. p. 33-45. TOZONI-REIS, Marília de Freitas Campos. et al. Conteúdos curriculares da educação ambiental na escola: contribuições da pedagogia histórico-crítica. Em: VII Encontro de Pesquisa em Educação Ambiental, EPEA, 2013, Rio Claro - SP. Anais... 2013. Disponível em: <http://www.epea.tmp.br/epea2013_anais/pdfs/plenary/0190-1.pdf>. Acesso em: 04 fev. 2014.

VIEIRA, Emília Peixoto. Gramsci e suas contribuições para a compreensão do trabalho docente. Revista Trabalho e Educação, v. 17, n. 1, jan./abr. 2008. 